\title{
Vitamin D Deficiency is Correlated with Poor Outcomes in Patients with Luminal-type Breast Cancer
}

\author{
Hee Jeong Kim, MD, PhD ${ }^{1}$, Yu Mi Lee, MD¹, Beon Seok Ko, MD ${ }^{1}$, Jong Won Lee, MD ${ }^{1}$, Jong Han Yu, MD ${ }^{1}$, \\ Byung Ho Son, MD, PhD ${ }^{1}$, Gyung-Yub Gong, MD, $\mathrm{PhD}^{2}$, Sung Bae Kim, MD, $\mathrm{PhD}^{3}$, and Sei Hyun Ahn, $\mathrm{MD} \mathrm{PhD}^{1}$ \\ ${ }^{1}$ Department of Surgery, Asan Medical Center, University of Ulsan, College of Medicine, Seoul, Korea; ${ }^{2}$ Department of \\ Pathology, Asan Medical Center, University of Ulsan, College of Medicine, Seoul, Korea; ${ }^{3}$ Department of Oncology, Asan \\ Medical Center, University of Ulsan, College of Medicine, Seoul, Korea
}

\begin{abstract}
Purpose. Vitamin D deficiency may be an indicator of poor prognosis in patients with breast cancer before surgery. We investigated the association between serum vitamin $\mathrm{D}$ concentration and breast cancer prognosis according to intrinsic cancer subtypes.

Methods. From June to December 2006, serum 25-OHD was measured in 310 Korean women with breast cancer who were treated at the Asan Medical Center, Korea. Clinicopathologic data were examined to determine the prognostic effects of serum 25-OHD. Expression of estrogen receptor (ER), progesterone receptor (PR), and epidermal growth factor receptor 2 (Her2) were measured using tissue microarrays. Patients were classified with luminal A, luminal B, Her2-enriched, or basal-like subtypes of breast cancer.
\end{abstract}

Results. Mean patient age was 48.7 years, and mean serum 25-OHD concentration was $31.4 \pm 16.1 \mathrm{ng} / \mathrm{ml}$. The 25-OHD levels were deficient $(<20 \mathrm{ng} / \mathrm{ml})$ in 75 patients $(24.2 \%)$, insufficient $(20-29 \mathrm{ng} / \mathrm{ml})$ in $95(30.6 \%)$, and sufficient $(30-150 \mathrm{ng} / \mathrm{ml})$ in $140(45.2 \%)$. Women with deficient 25-OHD levels were at increased risk of recurrence compared with those with sufficient vitamin D levels $(P=0.002)$. The $25-\mathrm{OHD}$ concentration was inversely associated with prognosis of patients with cancer of the

Presented in part at the 32nd Annual Meeting of the San Antonio Breast Cancer Symposium.

(C) The Author(s) 2010. This article is published with open access at Springerlink.com

First Received: 27 August 2010;

Published Online: 14 December 2010

S. H. Ahn, MD, PhD

e-mail: ahnsh@amc.seoul.kr luminal A $(P=0.012)$ and luminal B subtypes $(P=0.023)$, but not with the prognosis of patients with Her2/neu-enriched $(P=0.245)$ or triple-negative $(P=$ 0.879 ) cancer subtypes. This association remained valid after adjustment for age, tumor size, nodal status, and estrogen receptor status (hazards ratio $=3.97$; $95 \%$ confidence interval $=$ 1.77-9.61).

Conclusions. Vitamin D deficiency may be associated with poor outcomes in patients with luminal-type breast cancer.

Humans obtain vitamin D primarily by exposure of the skin surface to ultraviolet $B$ radiation, with small amounts ingested from dietary sources and supplements. Vitamin $\mathrm{D}_{3}$ is activated in the body in two metabolic steps. In the first step, which takes place in the liver, vitamin D is converted to its major circulating metabolite, $25-\mathrm{OHD}_{3}$. In the second step, occurring in the kidneys, circulating $25-\mathrm{OHD}_{3}$ is converted to $1 \alpha, 25-(\mathrm{OH})_{2} \mathrm{D}_{3}$, the active hormonal form of vitamin $\mathrm{D}$. Another biologically active metabolite, 1,25$(\mathrm{OH}) 2 \mathrm{D}$, binds to nuclear vitamin D receptors (VDRs) in the intestines, bone, breast, and other tissues. In vitro, 1,25$(\mathrm{OH})_{2} \mathrm{D}$ has been shown to inhibit cell proliferation and to promote apoptosis and cell differentiation in breast tumor tissue, providing a biologic basis for an epidemiologic study of the relationship between vitamin D concentration and breast cancer. ${ }^{1}$

Vitamin D concentration may be a risk and/or a valuable prognostic factor in patients with breast cancer. Many epidemiologic, preclinical, and clinical studies have suggested that vitamin D deficiency may be involved in breast cancer initiation, progression, and prognosis, whereas other studies, including a randomized, controlled trial, showed no such association. However, the impact of vitamin D 
levels on breast cancer recurrence and death has not been adequately addressed, although one study found that women with deficient levels of vitamin D were at increased risk of distant recurrence and death compared with women with sufficient levels of vitamin D. ${ }^{2}$ An understanding of the prognostic significance of vitamin D deficiency in patients with breast cancer may identify a high-risk patient subgroup.

Ethnic/racial variations in the association of vitamin D concentration and breast cancer also may occur. The proportion of patients with breast cancer diagnosed at a younger age is notably higher in Asian than in western countries. Exposure to sunlight is notably lower in Asia than in the west. Asians have a higher prevalence of milk intolerance and use of vitamin D supplements is rare, especially among Koreans. Apart from a Japanese study that showed an association between vitamin D concentration and breast cancer risk, few epidemiologic efforts have investigated such an association in Asian women. ${ }^{3} \mathrm{We}$ therefore explored the prognostic significance of vitamin D concentration in Korean patients with breast cancer. We also determined whether the effects of vitamin D differed among patients with various intrinsic subtypes of breast cancer.

\section{PATIENTS AND METHODS}

Our study protocol was approved by the Institutional Review Board of the Asan Medical Center, Seoul, Korea.

\section{Study Population}

Patients were drawn from the Asan Medical Center Breast Cancer Center database-a prospectively maintained web-based system, which includes information on all patients who underwent surgery for breast cancer at the Asan Medical Center since 1989. The database provides detailed information on the type and date of breast cancer recurrence and the date of last follow-up.

We retrospectively reviewed the outcomes of 310 Korean women who were diagnosed with breast cancer between June and December 2006. Of these, 36 patients had ductal carcinoma in situ (DCIS) and 261 had invasive breast cancer. Patients were staged according to the sixth edition of the American Joint Committee on Cancer staging system for invasive breast cancer.

\section{Measurements}

Serum 25-OHD was measured using a radioimmunoassay kit (BioSource, Belgium) before surgery. Although no consensus on optimal levels of serum 25-OHD exists, vitamin D deficiency is defined as $<20 \mathrm{ng} / \mathrm{ml}(50 \mathrm{nmol} / \mathrm{l})$.
Because an increase in average 25-OHD concentration from $20 \mathrm{ng} / \mathrm{ml}$ to $32 \mathrm{ng} / \mathrm{ml}$ increased intestinal calcium transport by $45-60 \%$ in women, a $25-O H D$ concentration of $21-29 \mathrm{ng} / \mathrm{ml}(50-72 \mathrm{nmol} / \mathrm{l})$ has been considered to be insufficient, and a level $\geq 30 \mathrm{ng} / \mathrm{ml}$ adequate. Vitamin D intoxication is observed when serum levels of 25-OHD exceed $150 \mathrm{ng} / \mathrm{ml}$ (374 nmol/l). As in a previous study, we used these concentrations to sort patients. ${ }^{2}$

\section{Immunohistochemical Staining}

Immunohistochemical staining for estrogen receptor (ER), progesterone receptor (PR), and Her2/neu was performed using arrayed tissue blocks. Briefly, formalin-fixed, paraffin-embedded tissue sections, 5- $\mu \mathrm{m}$ thick, were obtained using a microtome, transferred to adhesive slides, and dried at $62^{\circ} \mathrm{C}$ for $30 \mathrm{~min}$. Sections were incubated, using a benchmark automatic immunostaining device (Ventana Medical Systems, Tucson, AZ), with primary antibodies against ER (1:50 dilution; Diona, Seoul, Korea), PR (1:100 dilution; Diona), and Her2/neu (1:250 dilution; DAKO), followed sequentially by incubation with biotinylated anti-mouse immunoglobulin and peroxidase-labeled streptavidin, using 3.3'-diaminobenzidine chromogen as the substrate. Samples were considered positive for Her2/ neu when strong $(3+)$ membranous staining was observed in a least $10 \%$ of tumor cells, whereas those with staining of grades 0 to $2+$ were regarded as negative.

Breast cancer samples were categorized into molecular subtypes based on immunohistochemical profiles. Samples that were ER- or PR-positive and Her2/neu-negative were classified as luminal A, samples that were ER- or PRpositive and Her2/neu-positive were classified as luminal B, samples that were ER- and PR-negative and Her2/neupositive were classified as Her2-enriched, and samples that were ER-, PR-, and Her2/neu-negative were classified as triple-negative.

\section{Statistical Analysis}

Patients were classified based on serum 25-OHD concentration into those with sufficient (30-150 ng/ml), insufficient (20-29 ng/ml), or deficient $(<20 \mathrm{ng} / \mathrm{ml})$ levels of serum 25-OHD. Disease-free survival was defined as the time from surgery to the date of the first locoregional recurrence, distant metastasis, detection of a secondary primary tumor, or death from any cause. Any recurrence at a site, including the contralateral axillary and supraclavicular lymph nodes, was considered a distant metastasis, whereas recurrence in a remnant breast, the chest wall, or the axillary or ipsilateral supraclavicular lymph node was considered a locoregional recurrence. The $\chi^{2}$ test and analysis of variance (ANOVA) were used to evaluate the 
significance of differences in clinicopathologic features between groups. Univariate survival was analyzed using the Kaplan-Meier method and log-rank tests were employed to compare survival curves. Multivariate analyses were conducted using Cox's proportional hazard regression model. All statistical analyses were performed by using SPSS version 12.0 (SPSS, Chicago, IL).

\section{RESULTS}

\section{Vitamin D Levels}

The mean age of the 310 patients was $48.9 \pm$ 10.3 years, and the mean vitamin $\mathrm{D}$ concentration was $31.4 \pm 16.1$ (range, 4.8-109) $\mathrm{ng} / \mathrm{ml}$. Vitamin D levels were deficient $(<20 \mathrm{ng} / \mathrm{ml})$ in 75 patients $(24.2 \%)$, insufficient $(20-29 \mathrm{ng} / \mathrm{ml})$ in 95 patients $(30.6 \%)$, and adequate (30-150 ng/ml) in 140 patients (45.2\%). No patient experienced vitamin $\mathrm{D}$ intoxication (vitamin $\mathrm{D}>150 \mathrm{ng} / \mathrm{ml}$ ). Although body mass index (BMI) was not correlated with vitamin $\mathrm{D}$ concentration, patients in the adequate vitamin D group were usually within the normal range of BMI (Table 1).

\section{Association of Vitamin D Levels with Tumor Characteristics}

There were no significant correlations between vitamin $\mathrm{D}$ concentration and $\mathrm{T}$ stage, tumor grade, or intrinsic subtypes. Lymph node metastasis was more frequent in the vitamin D-sufficient group than in other groups $(P=0.017$; Table 1). However, when patients were separated by intrinsic tumor type, the relationship between vitamin $\mathrm{D}$ level and lymph node metastasis was significant only for nonluminal subtypes $(P=0.008)$ and not for luminal types of breast cancer $(P=0.217)$.

\section{Prognostic Associations of Vitamin D Level}

Of our 310 patients, $31(10 \%)$ experienced metastasis and $9(2.9 \%)$ died after a median follow-up time of 23 months. Of these nine patients, two died without documented spread of breast cancer.

We found that vitamin D concentration was a significant predictor of disease-free survival. Women with sufficient levels of vitamin D had significantly better disease-free survival than women with deficient levels $(P=0.002$; Fig. 1). Of the five patients who developed a second primary cancer, four had deficient concentrations of vitamin $\mathrm{D}$ $(P=0.012$; Table 2$)$. One patient who had sufficient concentrations of vitamin $\mathrm{D}$ had pancreas cancer 19 months after breast cancer diagnosis.
TABLE 1 Clinicopathologic and treatment-related factors in the three 25-OHD groups

\begin{tabular}{|c|c|c|c|c|c|c|c|}
\hline & \multicolumn{2}{|c|}{ Deficient } & \multicolumn{2}{|c|}{ Insufficient } & \multicolumn{2}{|c|}{ Sufficient } & \multirow[t]{2}{*}{$P$ value } \\
\hline & No. & $\%$ & No. & $\%$ & No. & $\%$ & \\
\hline $\begin{array}{c}\text { Mean age } \\
\text { (years) }\end{array}$ & 48.7 & $(+10.3)$ & 47.8 & $(+9.4)$ & 49.6 & $(+10.8)$ & 0.409 \\
\hline $\begin{array}{l}\text { Mean tumor } \\
\text { size }(\mathrm{cm})\end{array}$ & 1.8 & +1.6 & 2 & +1.6 & 2.1 & +1.6 & 0.449 \\
\hline BMI $\left(\mathrm{kg} / \mathrm{m}^{2}\right)$ & & & & & & & 0.087 \\
\hline$\leq 25$ & 65 & 86.7 & 76 & 80 & 99 & 70.7 & \\
\hline $25-30$ & 8 & 10.7 & 17 & 17.9 & 34 & 24.3 & \\
\hline$>30$ & 2 & 2.7 & 2 & 2.1 & 7 & 5 & \\
\hline T stage & & & & & & & 0.18 \\
\hline T0 & 8 & 10.7 & 13 & 13.7 & 12 & 8.6 & \\
\hline $\mathrm{T} 1$ & 43 & 57.3 & 46 & 48.4 & 68 & 48.6 & \\
\hline $\mathrm{T} 2$ & 21 & 28 & 28 & 29.5 & 56 & 40 & \\
\hline T3 & 3 & 4 & 8 & 8.4 & 4 & 2.9 & \\
\hline LN metastasis & & & & & & & 0.017 \\
\hline Negative & 48 & 64 & 63 & 66.3 & 69 & 49.3 & \\
\hline Positive & 27 & 36 & 32 & 33.7 & 71 & 50.7 & \\
\hline Grade & & & & & & & 0.136 \\
\hline Low (1-2) & 36 & 54.5 & 50 & 61 & 88 & 68.8 & \\
\hline High (3) & 30 & 45.5 & 32 & 39 & 40 & 31.3 & \\
\hline $\begin{array}{l}\text { Intrinsic } \\
\text { subtype }\end{array}$ & & & & & & & 0.282 \\
\hline Luminal A & 34 & 45.9 & 46 & 49.5 & 61 & 43.6 & \\
\hline Luminal B & 19 & 25.7 & 23 & 24.7 & 35 & 25 & \\
\hline $\begin{array}{l}\text { Her2/neu } \\
\text { enriched }\end{array}$ & 7 & 9.5 & 17 & 18.3 & 26 & 18.6 & \\
\hline $\begin{array}{l}\text { Triple } \\
\text { negative }\end{array}$ & 14 & 18.9 & 7 & 7.5 & 18 & 12.9 & \\
\hline
\end{tabular}

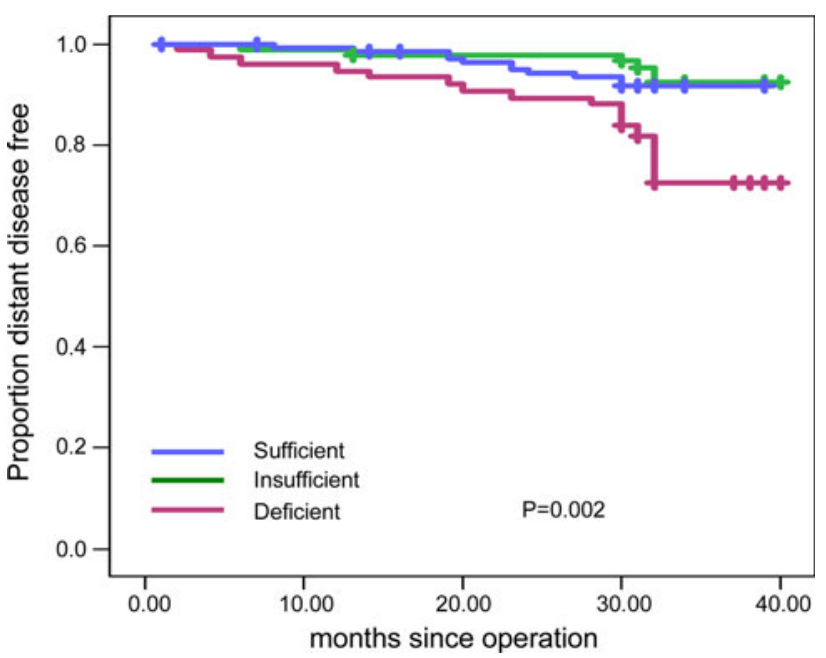

FIG. 1 Univariate analysis of disease-free survival according to vitamin D status 
TABLE 2 Nonbreast second malignancies in the three 25-OHD groups

\begin{tabular}{|c|c|c|c|c|c|c|c|}
\hline & \multicolumn{2}{|c|}{ Deficient } & \multicolumn{2}{|c|}{ Insufficient } & \multicolumn{2}{|c|}{ Sufficient } & \multirow[t]{2}{*}{$P$ value } \\
\hline & No. & $\%$ & No. & $\%$ & No. & $\%$ & \\
\hline $\begin{array}{l}\text { Nonbreast second } \\
\text { malignancies }\end{array}$ & 4 & 5.3 & 0 & 0 & 1 & 0.7 & 0.012 \\
\hline
\end{tabular}

Vitamin D status was prognostic in patients with breast cancer of luminal types A and B but not in patients with triple-negative or Her2/neu-enriched cancer subtypes. No evidence could be adduced to indicate that the prognostic effects of vitamin D were related to Her2/neu status (Fig. 2). In patients with luminal types of breast cancer, deficient concentrations of vitamin $\mathrm{D}$ were associated with significantly lower disease-free survival times $(P=0.004)$. This association was not observed in patients with nonluminal types of breast cancer $(P=0.475$; Fig. 3$)$.

Multivariate analysis, after adjusting for age, $\mathrm{LN}$ positivity, ER status, and T stage, showed that a deficient level of vitamin $\mathrm{D}$ was an independent prognostic indicator of
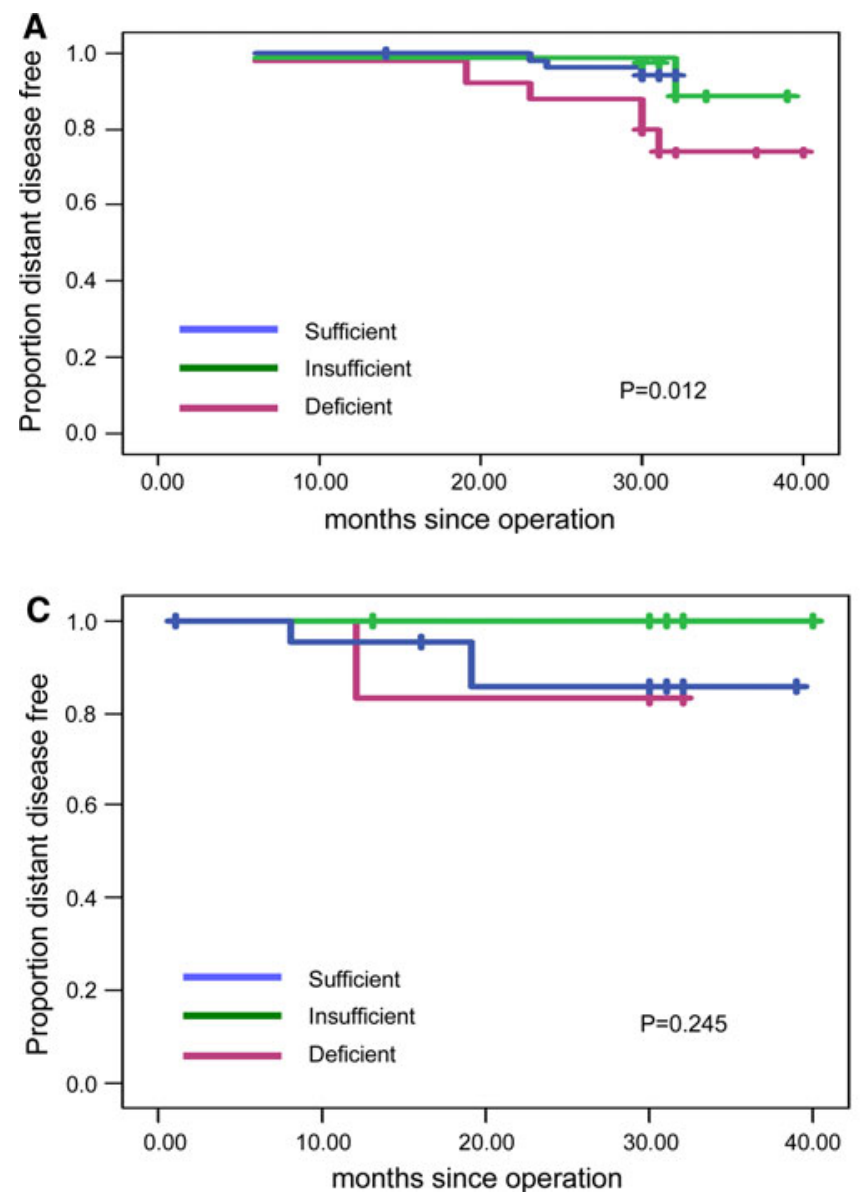

breast cancer recurrence (hazards ratio (HR) 3.97; $95 \%$ confidence interval $(\mathrm{CI})=1.76-8.91$; Table 3 ).

\section{DISCUSSION}

We have shown that deficient serum concentrations of vitamin $\mathrm{D}$ were significantly associated with an increased risk of distant recurrence of breast cancer compared with patients who had adequate levels of vitamin D. Furthermore, the prognostic association varied with intrinsic subtype-significant only for patients with luminal types of breast cancer. To the best of our knowledge, the present study is the first to show that vitamin D concentration is a valuable prognostic indicator in estimation of survival, depending on breast cancer intrinsic subtype.

Although several epidemiologic studies have evaluated associations between vitamin D concentration, breast cancer risk, and prognosis, the cited works have yielded inconsistent results. ${ }^{4}$ Among methodologic inconsistencies evident in these studies are evaluation of vitamin D status; some works assessed the effects of dietary or supplemental intake of vitamin D and others explored vitamin D status
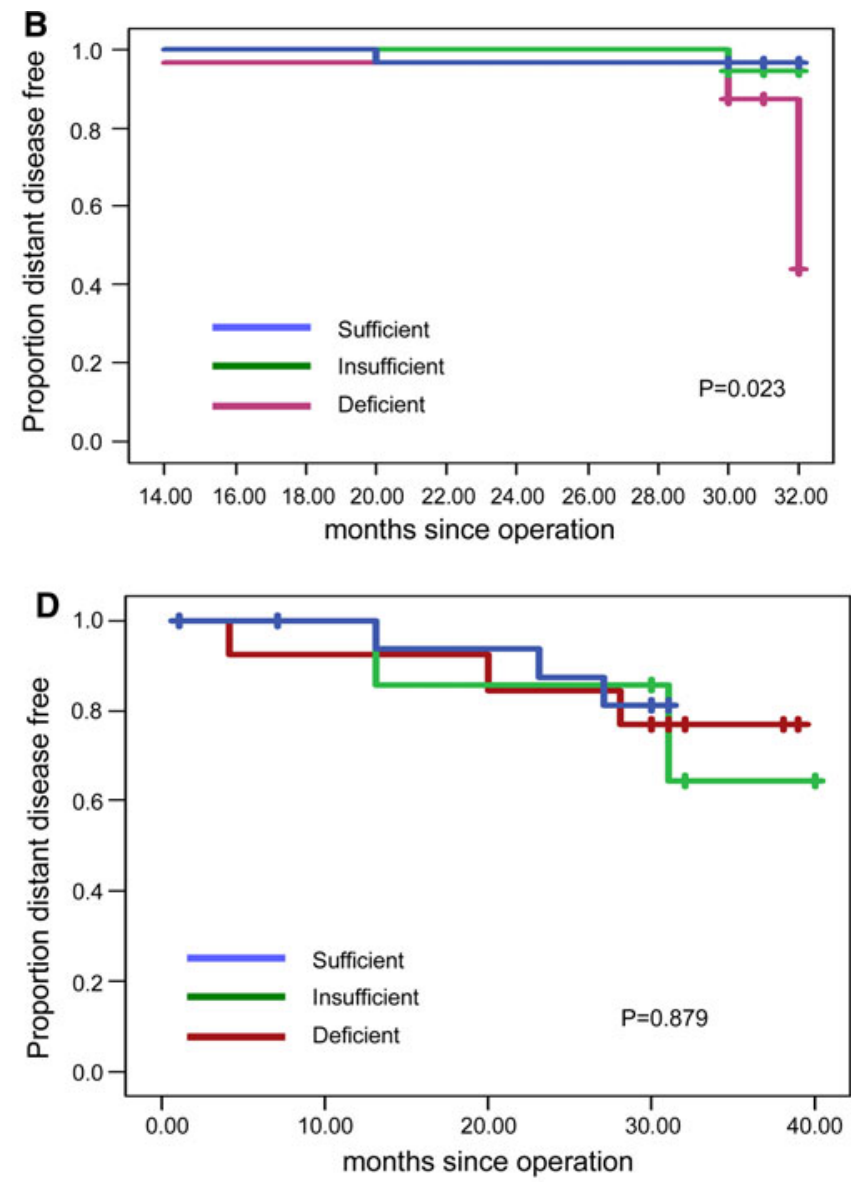

FIG. 2 Disease-free survival and vitamin D status with respect to intrinsic breast cancer subtype. a Luminal A. b Luminal B. c Her2/neuenriched. d Triple-negative 

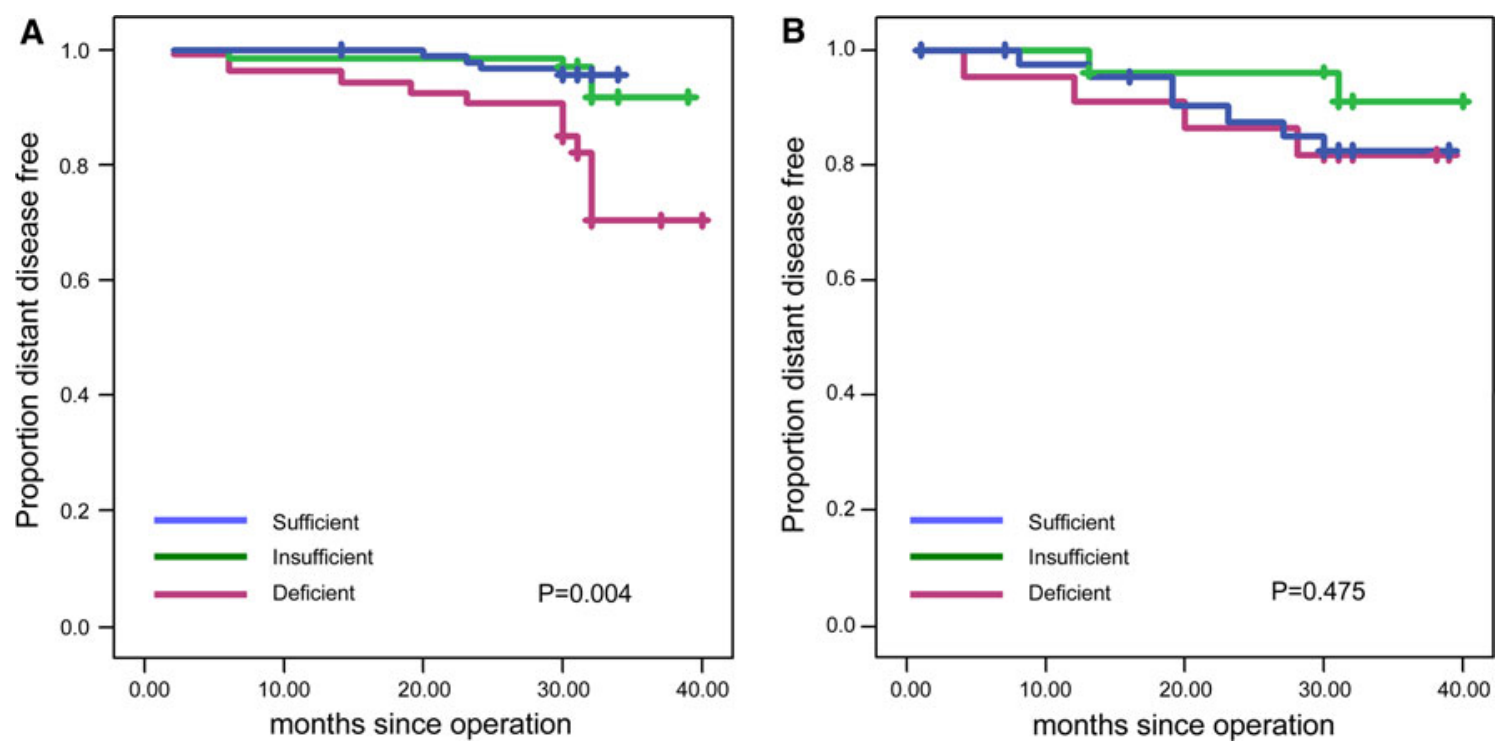

FIG. 3 Disease-free survival and vitamin D status in a hormone receptor-positive and $\mathbf{b}$ hormone receptor-negative patients

TABLE 3 Results of Cox proportional hazard regression modeling according to $25 \mathrm{OHD}$ status

\begin{tabular}{lllll}
\hline Characteristic & Weight category & \multicolumn{4}{l}{ Disease-free survival } \\
\cline { 3 - 5 } & & HR & $95 \%$ CI & $P$ value \\
\hline Vitamin D & Sufficient & Reference & & \\
& Insufficient & 0.82 & $0.28-2.37$ & 0.711 \\
& Deficient & 3.97 & $1.77-8.91$ & 0.001 \\
Age (years) & & 1.01 & $0.98-1.04$ & 0.535 \\
LN positivity & & 4.18 & $1.8-9.72$ & 0.001 \\
ER negativity & & 1.88 & $0.9-3.9$ & 0.093 \\
Tumor size $(\mathrm{cm})$ & 1.12 & $0.95-1.33$ & 0.19 \\
\hline
\end{tabular}

with respect to sunlight exposure. Measurement of circulating concentrations of 25-OHD provides an integrated measure of vitamin $\mathrm{D}$ derived from all sources, including sunlight exposure, diet, and supplementation, and is considered the best indicator of vitamin D body stores. ${ }^{5-7}$ The cited epidemiologic studies also used different categorizations of vitamin D status, and one work, similar to the present report, categorized vitamin D status by serum 25OHD concentration as deficient, insufficient, and sufficient. $^{2}$

Several epidemiologic studies have shown conflicting results between vitamin $\mathrm{D}$ and hormone receptor-defined breast cancer. Increased intake of vitamin D was found to be consistently associated with a significantly reduced risk of $\mathrm{ER}+/ \mathrm{PR}+$ tumors, and dietary vitamin D level was inversely related to the risk of ER+ tumors. ${ }^{8,9}$ A recent Japanese study reported that ER+ and/or PR+/Her2breast cancer frequency was significantly associated with vitamin $\mathrm{D}$ intake in premenopausal women. ${ }^{3}$ In contrast, the Iowa Women's health study found an inverse, but statistically insignificant, association between high vitamin D intake and ER- or PR-type tumors. ${ }^{10}$ A case series showed that the triple-negative breast cancer phenotype was associated with the lowest average serum vitamin D concentration and the highest percentage of vitamin Ddeficient patients. ${ }^{11}$ However, the cited study included fewer patients with the triple-negative phenotype $(N=15)$ than were evaluated in the present work $(N=39)$.

In this study, we found that vitamin D level was prognostic in all patients with breast cancer, but the concentration was not significantly prognostic in patients with triple-negative and Her2/neu-enriched subtypes. One plausible explanation is that vitamin D acts synergistically to suppress the effects of estrogen in patients with luminaltype breast cancer. The antiproliferative and antitumor effects of vitamin D on estrogen-responsive breast cancer cells are mediated by disruption of estrogen mitogenic and survival signals. A potential vitamin D receptor element has been identified within the ER promoter gene, suggesting that 1,25- $(\mathrm{OH}) 2 \mathrm{D} 3$ may directly regulate ER gene transcription. $^{12}$ Vitamin $\mathrm{D}$ reduces the expression and biological activity of prostaglandins and decreases synthesis of aromatase, in addition to suppressing the proliferative activity of 17ß-estradiol and downregulating the level of the estrogen receptor. ${ }^{13,14}$ Moreover, higher concentrations of 25-(OH)D have been shown to significantly lower serum luteal progesterone and estrogen levels. This may represent a mechanism by which higher $25-(\mathrm{OH}) \mathrm{D}$ levels in young women may reduce subsequent breast cancer risk. ${ }^{15}$ Furthermore, sensitivity to $1,25-(\mathrm{OH}) \mathrm{D} 3$ is generally higher in breast cancer cells that express estrogen receptor than in cells that do not synthesize the protein. ${ }^{16,17}$ 
Vitamin D has been associated with breast cancer metastasis and drug response. Vitamin D has been shown to inhibit invasion and metastasis by reducing the activity of MMP-9, UPA, and TPA, and by increasing the levels of PA inhibitor 1, MMP inhibitor 1, and general antiangiogenic activity. ${ }^{14}$ Moreover $1,25-(\mathrm{OH}) 2 \mathrm{D} 3$ has been shown to enhance the sensitivity of breast cancer cells to several anticancer drugs and other agents. Vitamin D compounds have been demonstrated to potentiate apoptosis induced by adriamycin, Taxol, radiation, and tamoxifen. ${ }^{18-20}$ These findings indicate that maintenance of adequate vitamin D concentrations during adjuvant treatment may enhance the effects of such treatment and prolong survival.

We found that patients with vitamin D deficiency developed significantly more frequent second primary cancers than did patients with sufficient vitamin D concentration. Vitamin D deficiency also has been associated with an increased risk of Hodgkin's lymphoma as well as colon, prostate, ovarian, breast, and other cancers. ${ }^{21} \mathrm{Sec}-$ ondary cancers are among the most threatening long-term health problems in patients with breast cancer. Moreover, some breast cancer treatment regimens are associated with an increased risk of osteoporosis, which also can be caused by vitamin D deficiency. Such deficiency has been associated with an increased level of depression and overall mortality in the general population. ${ }^{22}$ Therefore, correction of vitamin D status may be important not only for survival but to improve quality of life in patients with breast cancer. One study, in which patients who received adjuvant chemotherapy were prescribed vitamin D3 at $400 \mathrm{IU}$ for 1 year found that fewer than $15 \%$ of such patients achieved sufficient 25-OHD levels, indicating that the currently recommended doses of vitamin $\mathrm{D}$ are not adequate to positively affect bone health or to improve survival. ${ }^{7}$ Safety is an important consideration when recommending nutrient intake. Vitamin D intoxication is extremely rare but can be caused by inadvertent or intentional ingestion of excessively high doses. ${ }^{23}$ However, a recent review found no reports of toxicity in patients taking $<20,000$ IU per day of vitamin $\mathrm{D}$ or in those with a serum 25-OHD concentration $<200 \mathrm{ng} / \mathrm{ml}$ during an extended period. ${ }^{24}$

Differences in the prevalence of vitamin D insufficiency have been associated with various factors, including age, race, BMI, exposure to sun, geographic location, dietary vitamin D intake, daily activity, and exercise level. Korea lies at latitudes of 33-43 degrees north and thus is considered to enjoy abundant sunlight. Oriental culture, however, does not encourage exposure of skin to the sun, especially in women. ${ }^{25,26}$ Moreover, milk intolerance is more prevalent in Koreans than in western populations. Although deficient vitamin D status has been associated with obesity in western women, we found no such relationship among our patients. The relationship between BMI and fat levels in Asian women differs significantly from that in white females. ${ }^{27,28}$ Although a previous study reported that $92 \%$ of Korean women had vitamin D concentrations $<75 \mathrm{nmol} / 1$, vitamin D status improved after patients were educated on the importance of vitamin D ingestion and dietary supplementation. Furthermore, exercise can increase serum 25-OHD concentrations. $^{29}$ These findings indicate that vitamin D deficiency can be overcome by education, lifestyle modification, and dietary supplementation regardless of racial differences.

Our findings also indicate the importance of prospective, randomized studies to determine vitamin $\mathrm{D}$ concentrations that can predict the outcomes of patients with breast cancer, as well as the level of vitamin D supplementation required by vitamin D-deficient patients. Randomized studies are required to determine the effects of increasing vitamin $\mathrm{D}$ levels on cancer risk and prognosis. The size and duration of cancer prevention trials, along with intrinsic problems in long-term adherence to assigned protocols, may limit the ability of such efforts to address many important questions, especially those related to behavioral changes. Therefore, patients with breast cancer should be educated on lifestyle changes, including exposure to sunlight, eating habits, and dietary supplementation that may prolong survival. Moreover, vitamin D concentrations should be measured regularly, and, if necessary, such patients should be given vitamin $\mathrm{D}$ supplements.

The present study had several limitations. Vitamin D concentration was measured only before surgery and not during follow-up. Adjuvant chemotherapy has been found to reduce plasma vitamin $\mathrm{D}$ concentration significantly. ${ }^{30}$ Therefore, the prognostic significance of changes in vitamin D status, especially in vitamin D-deficient patients, remains to be determined. Circulating concentrations of vitamin $\mathrm{D}$ should be measured in all patients with breast cancer, not only before commencement of treatment but also during adjuvant procedures, and during follow-up periods. Second, because all patients of the present study were of Korean nationality, thus all ethnically homogeneous Far East Asians, we cannot state whether our results can be applied to other ethnic groups and countries.

In conclusion, our findings suggest that deficient vitamin $\mathrm{D}$ status is a high-risk factor for recurrence in patients with breast cancer, especially those with hormone receptorpositive breast cancer. These observational findings may benefit patients with hormone receptor-positive breast cancer by encouraging dietary supplementation to maintain adequate vitamin D levels. Vitamin D status should be measured during follow-up to optimize patient outcomes and reduce mortality. 
OPEN ACCESS This article is distributed under the terms of the Creative Commons Attribution Noncommercial License which permits any noncommercial use, distribution, and reproduction in any medium, provided the original author(s) and source are credited.

\section{REFERENCES}

1. Kemmis CM, Welsh J. Mammary epithelial cell transformation is associated with deregulation of the vitamin D pathway. $J$ Cell Biochem. 2008;105(4):980-8.

2. Goodwin PJ, Ennis M, Pritchard KI, Koo J, Hood N. Prognostic Effects of 25-Hydroxyvitamin D Levels in Early Breast Cancer. $J$ Clin Oncol. 2009;27(23):3757-63.

3. Kawase T, Matsuo K, Suzuki T, et al. Association between vitamin $\mathrm{D}$ and calcium intake and breast cancer risk according to menopausal status and receptor status in Japan. Cancer Sci. 2010;101(5):1234-40.

4. Cui Y, Rohan TE. Vitamin D, calcium, and breast cancer risk: a review. Cancer Epidemiol Biomarkers Prevent. 2006;15(8): 1427-37.

5. Iqbal SJ. Vitamin D metabolism and the clinical aspects of measuring metabolites. Ann Clin Biochem. 1994;31(Pt 2):109-24.

6. Hollis BW. Assessment of vitamin D nutritional and hormonal status: what to measure and how to do it. Calcif Tissue Int. 1996; 58(1):4-5.

7. Crew KD, Gammon MD, Steck SE, et al. Association between plasma 25-hydroxyvitamin D and breast cancer risk. Cancer Prev Res. 2009;2(6):598-604.

8. Blackmore KM, Lesosky M, Barnett H, Raboud JM, Vieth R, Knight JA. Vitamin D from dietary intake and sunlight exposure and the risk of hormone-receptor-defined breast cancer. Am J Epidemiol. 2008;168(8):915-24.

9. McCullough ML, Rodriguez C, Diver WR, et al. Dairy, calcium, and vitamin $\mathrm{D}$ intake and postmenopausal breast cancer risk in the Cancer Prevention Study II Nutrition Cohort. Cancer Epidemiol Biomarkers Prevent. 2005;14(12):2898-904.

10. Robien K, Cutler GJ, Lazovich D. Vitamin D intake and breast cancer risk in postmenopausal women: the Iowa Women's Health Study. Cancer Causes Control. 2007;18(7):775-82.

11. Rainville $\mathrm{C}$, Khan Y, Tisman G. Triple negative breast cancer patients presenting with low serum vitamin D levels: a case series. Cases J. 2009;2:8390.

12. Stoica A, Saceda M, Fakhro A, Solomon HB, Fenster BD, Martin MB. Regulation of estrogen receptor-alpha gene expression by 1,25-dihydroxyvitamin D in MCF-7 cells. $J$ Cell Biochem. 1999;75(4):640-51.

13. Krishnan AV, Swami S, Feldman D. Vitamin D and breast cancer: inhibition of estrogen synthesis and signaling. J Steroid Biochemistry Molecul Biol. 2010;121(1-2):343-8.

14. Colston K, Hansen C. Mechanisms implicated in the growth regulatory effects of vitamin D in breast cancer. Endocr Relat Cancer. 2002;9(1):45-59.
15. Knight JA, Wong J, Blackmore KM, Raboud JM, Vieth R. Vitamin D association with estradiol and progesterone in young women. Cancer Causes Control. 2010;21(3):479-83.

16. Narvaez CJ, Zinser G, Welsh J. Functions of 1alpha,25-dihydroxyvitamin $\mathrm{D}(3)$ in mammary gland: from normal development to breast cancer. Steroids. 2001;66(3-5):301-8.

17. Narvaez CJ, Welsh J. Role of mitochondria and caspases in vitamin D-mediated apoptosis of MCF-7 breast cancer cells. $J$ Biol Chem. 2001;276(12):9101-7.

18. Sundaram S, Chaudhry M, Reardon D, Gupta M, Gewirtz DA. The vitamin D3 analog EB 1089 enhances the antiproliferative and apoptotic effects of adriamycin in MCF-7 breast tumor cells. Breast Cancer Res Treat. 2000;63(1):1-10.

19. Sundaram S, Gewirtz DA. The vitamin D3 analog EB 1089 enhances the response of human breast tumor cells to radiation. Radiat Res. 1999;152(5):479-86.

20. Wang Q, Yang W, Uytingco MS, Christakos S, Wieder R. 1,25Dihydroxyvitamin D3 and all-trans-retinoic acid sensitize breast cancer cells to chemotherapy-induced cell death. Cancer Res. 2000;60(7):2040-8.

21. Holick MF. Vitamin D and sunlight: strategies for cancer prevention and other health benefits. Clin J Am Soc Nephrol. 2008;3(5):1548-54.

22. Nanri A, Mizoue T, Matsushita Y, et al. Association between serum 25-hydroxyvitamin D and depressive symptoms in Japanese: analysis by survey season. Eur J Clin Nutr. 2009;63(12): 1444-7.

23. Holick MF. Vitamin D deficiency. $N$ Engl J Med. 2007;357(3): 266-81.

24. Hathcock JN, Shao A, Vieth R, Heaney R. Risk assessment for vitamin D. Am J Clin Nutr. 2007;85(1):6-18.

25. Kim MK, Kang MI, Oh KW, et al. The association of serum vitamin D level with presence of metabolic syndrome and hypertension in middle-aged Korean subjects. Clin Endocrinol (Oxf). 2010;73(3):330-8.

26. Lee ES, Ahn J, Park HM. Serum vitamin D status of Korean postmenopausal women during the winter months. Asia Pac J Clin Nutr. 2009;18(1):29-33.

27. Ho-Pham LT, Lai TQ, Nguyen ND, Barrett-Connor E, Nguyen TV. Similarity in percent body fat between white and Vietnamese women: implication for a universal definition of obesity. Obesity (Silver Spring). 2010;18(6):1242-6.

28. Chung S, Song MY, Shin HD, et al. Korean and Caucasian overweight premenopausal women have different relationship of body mass index to percent body fat with age. J Appl Physiol. 2005;99(1):103-7.

29. Lym YL, Joh HK. Serum 25-hydroxyvitamin D3 is related to fish intake and exercise in Korean adult men. Asia Pac J Clin Nutr. 2009;18(3):372-6.

30. Santini D, Galluzzo S, Vincenzi B, et al. Longitudinal evaluation of vitamin D plasma levels during anthracycline- and docetaxelbased adjuvant chemotherapy in early-stage breast cancer patients. Ann Oncol. 2010;21(1):185-6. 